\title{
TOURISM EXPERIENCE IN INDONESIA: A NEW APPROACH USING THE RASCH MODEL SCALE
}

\author{
Bambang HERMANTO* \\ Universitas Padjadjaran, Business Administration Faculty of Social and Political Science, \\ Jatinangor, Sumedang, West Java, 45363, Indonesia, e-mail: b.hermanto@unpad.ac.id
}

Asep MIFTAHUDDIN

Department of Business Administration, Telkom University,

Bandung, Indonesia, e-mail: asepmiftahuddin@telkomuniversity.ac.id

\begin{abstract}
Citation: Hermanto, B., \& Miftahuddin, A. (2021). TOURISM EXPERIENCE IN INDONESIA: A NEW APPROACH USING THE RASCH MODEL SCALE. GeoJournal of Tourism and Geosites, 38(4), 1051-1056. https://doi.org/10.30892/gtg.38409-743
\end{abstract}

\begin{abstract}
In this paper, the research discussed analyzes the tourism experience in Indonesia, this study aims to explore the factors influencing the experience of city branding. The empirical application is based on a study of 373 visitors traveling in Indonesia, analyzed using the Rasch model. The present study aimed at a credible and accurate measurement scale that will help to clarify the definition and enhance the successful management of tourism experience. We have developed a 16-point size of tourism experience that we assume extends to many of the tourist destinations. The scale consists of six fields: hedonism, novelty, refreshment, local culture, significance, and dedication. Data are of assistance to the tourism experience's dimensional framework as well as its accuracy and validity within.
\end{abstract}

Key words: tourism experience, city branding, tourism, Rasch model, rating scale

$* \quad * \quad * \quad * \quad * \quad *$

\section{INTRODUCTION}

Currently, the tourism experience is needed in the development of city branding, as a consequence, the relevant stakeholders (managers of tourism businesses, government, and society) is required to collaborate, by selling the attractiveness of the city, into the main preferences of tourists who will visit, such as provide a quality experience high and memorable for travelers. According to Azara et al. (2018), the global economy has changed significantly in recent years, from service-based to one based on experience. This understanding continues to evolve into the needs of society to an emphasis on the consumption experience than the product. Following the phenomenon of focusing on the economy of experience, the research shows the effects of experience and how to calculate it (Brakus et al., 2009). Brakus et al., (2009) also created a four-dimensional brand experience by using the following dimensions (senses, mental, Behavioral, and academic). They noticed that it did not only do the person create feelings and perceptions of the brand, but also performs a physical activity relevant to the current quest, shop, and eat of the brand. In the tourism literature, Jung et al., (2016) developed a measurement tool that implements a four-dimensional experience of Pine and Gilmore (2011), which is aesthetic, educational, entertainment and escape. They argued that the four-year experience is relevant in the measurement of traveler experience.

The marketing literature review provides strategies that allow businesses to become or remain competitive in the international market. Scientists indicated that memory should strive to mediate behavioral intentions that should be implemented into the customer experience research (Manthiou et al., 2020). According to Kirillova and Wassler (2019), a memorable purchasing experience is important because (1) a high degree of motivation and engagement when knowledge is obtained from past experiences of individuals; (2) Aspects of psychology that previous experiences have proven to be highly trustworthy; and (3) mind-based experience has a major effect on future actions. When it comes to the setting of tourism, when it chooses to go and check for information that will be used to pick the area of interest, the person first receives experience (Al Mamun et al., 2018). Likewise, Pucihar et al. (2019) provide empirical evidence that illustrates the memorable experience is the strongest indicator of an individual's willingness to spend similar holidays throughout the future (Junaidi, 2020; Al-Hazmia, 2020; Nguyen et al., 2020; Setini et al., 2020). As a result, in order to establish a potential behavioral desire to visit a location, tourism businesses should focus on creating situations that will promote the delivery of positive experience in the field of tourism. A meaningful memorable vacation spot is described as a functional "tourism experience that is memorable and positively remembered after the event." They were often limited to those emotional emotions, such as relationships, joy, satisfaction, frustration, shame, sorrow, and fear (Olsson, 2016).

Consequently, to better understand the constituents of tourism experience, it is believed that the theoretical foundations of tourism experience would be further explored. Production and research processes and concurrent development of tourism assistance and tools for calculating scale testing should occur. It will help to develop a deeper understanding of this model, which, in turn, will strengthen and will enable tourism business managers and related stakeholders to properly resolve the challenges. With all of these considerations in mind, the objectives of this research are to improve the

\footnotetext{
* Corresponding author
} 
development of tourism literature on experience through the creation of a measuring instrument for assessing the experience of tourism as a constituent. In particular, this research aims to establish a scale of tourism experience that is accurate and reliable. For the first time, creating a conceptual Structure with this review, we are already providing a good historical overview of the experience of tourism and the related construction used to create a measuring tourism experience.

\section{MATERIALS AND METHODS}

\section{Tourism Experience}

Our recent trend in gaining a deeper understanding of tourism experience is the recent ongoing initiative to raise awareness of the basic "things" tourism is providing to its customers. Like Ritchie and Hudson (2009) pointed out, latest analyses of that same experience of founders, like Csikszentmihalyi (2009), Cohen (1979), and recent contributions (Chugh, 2018). Another recent contribution to classifying the attributes that affect the tourism experience (Lebrun et al., 2021; Ponte et al., 2021; Rasoolimanesh et al., 2021). We also assume that tourism experience is a new benchmark or quality that we all hope to reach. However, before we can reach this goal, we need to have a deeper understanding of the experience of tourism and to be able to calculate the modules. Tourism experience is primarily focused by tourism experience based on a review of individual experiences. In other words, the perception of tourism, defined as a personal mental condition felt by participants at service meetings, it is not difficult to convey it into tourism experience (Chugh, 2018).

There is also a major distinction between the two perspectives, especially with regard to those constituents of them. Jung et al. (2016) support that claim when they discuss the role of experience and brain dimensions. They noticed that only one dimension (i.e. aesthetics) had an impact on memory. Therefore, in order to better identify the elements of tourism experience that have a major impact on the individual, we also examine the subjective nature of tourism experience and previous research on the measurement in tourism experience. As reminded by Tresna et al. (2019), differences interest and history ratings perhaps result from a number of perceptions of the tourism service. In addition, visitors have a different point of view, even though they're doing the same thing in just the same place, since the environment and at a given moment, their personal emotions affect their perception of these encounters. And if all tourists claim they loved them on the tour, it doesn't imply that it would seem to have the same perceptions. As just a result, research into the fundamental mechanisms of tourist experience has changed out of the object supplied by the tourism industry to the subjective perception of the tourists' sense of the object (Vollero et al., 2018). By identifying these areas differently qualitatively where tourism is experienced by individuals, researchers also described tourism experience as contextual (Uriely, 2005).

\section{Characteristic Tourism Experience}

Studies have discovered various factors in the literature that enhances the memory of an incident. These involve feelings of love, cognitive assessment, and new events. Jepson and Sharpley (2015) found that emotional feelings are an important part of memory and experiences. Feelings are more likely to occur identified. From another experiment it is examined the efficacy of the common cues (i.e. objects, acts, and words of influence) in the creation of individual memory, Bowen (2019). By analyzing how memory is developed, Walters and Cassel (2016) found no association between cognitive processes and the intensity of memory of the individual. They define processing depth also as a level of semantic or cognitive testing that is an analysis of variance test method which improves or develops stimulation. Thus, the imagination consumes sensations that are recognized and significant at a deeper and faster rate.

It also holds better than less sensory cues. Finally, an irregular case, atypical or usual, is more likely to be seen than a regular occurrence. To support the previous discussion, the researcher's tourism study of the tourism experience discovered that affective feelings such as sociability, fun, happiness, upset, guilt, sadness, and anxiety, including in the tourism experience of individuals (Xie et al., 2013; Miftahuddin, 2021; Kóródi, 2020; Akay, 2020). Scientists have observed that when people did not specifically remember their perspectives (i.e. in which they were gone so when they came home) recalled positive as well as negative feelings about the journey. Centered on the theoretical models referred to above, 16 construction experience are suggested as part of the tourism experience seen in Table 1.

Table 1. The Preferred Attributes

\begin{tabular}{|c|l|c|}
\hline Construct & \multicolumn{1}{|c|}{ Items } & Code \\
\hline \multirow{3}{*}{ Hedonism } & I'm happy to visit that tourist attractions & N1 \\
\cline { 2 - 3 } & I feel very fortunate to be at a tourist attraction & N2 \\
\cline { 2 - 3 } & I would like to travel & N3 \\
\hline \multirow{3}{*}{ Novelty } & Attractions were offering new tours & N4 \\
\cline { 2 - 3 } & This tourist attraction is unique indeed & N5 \\
\cline { 2 - 3 } & Attractions are selling new experiences & N6 \\
\hline \multirow{3}{*}{ Local culture } & The tourist attraction family brings a better impression & N7 \\
\cline { 2 - 3 } & The tourist attraction family is friendly & N8 \\
\hline \multirow{3}{*}{ Meaningfulness } & Traveling removes exhaustion from the everyday routine & N9 \\
\cline { 2 - 3 } & Various options for tourist items & N10 \\
\cline { 2 - 3 } & Travel gets a new spirit & N11 \\
\cline { 2 - 3 } Involvement & Attractions were so important to be enjoyed & N13 \\
\hline \multirow{3}{*}{} & Tourist resources involve travelers in cultural attractions & N14 \\
\cline { 2 - 3 } & The tourist attraction has an outbound infrastructure & N15 \\
\cline { 2 - 3 } & Attractions provide travelers with new experiences & N16 \\
\hline
\end{tabular}

\section{METHOD}

This research is a quantitative descriptive study by looking at the field's facts (Al-Ansi et al., 2020; Chan et al., 2021; Soh et al., 2021; Stolt et al., 2021). The variables used in this study consist of the tourism experience variable. Data were collected through online surveys. The research location is in Jawa Barat, Indonesia. This research population is tourists visiting Jawa Barat with a total sample of 373 people, illustrated in Table 1 . Researchers use a systematic and sophisticated theoretical approach. Method to resolve the objectives of the report. This is made up of eight, as reported in Figure 1. Stage 1 specifies the domain and structures relevant to the encounter. Tourist inconvenience by evaluating previous literature and secondary data (i.e., newspapers and 
government reports). Stage 2 produces two focus group discussions with business, academics and experts, accompanied by semi-structured interviews with visitors. Stage 3 includes the administration of the first survey questionnaire. Finally, stage 4 consists of refining and purifying the produced items by face validity and feasibility and then removing unloaded or insufficient items according to the standard criteria. A second survey questionnaire, including additional structural designs, was administered at stage 5. Stage 6 carried out a solid evaluation of the variable used rasch analysis. Finally, tourism experience final version items were established in stage 7.

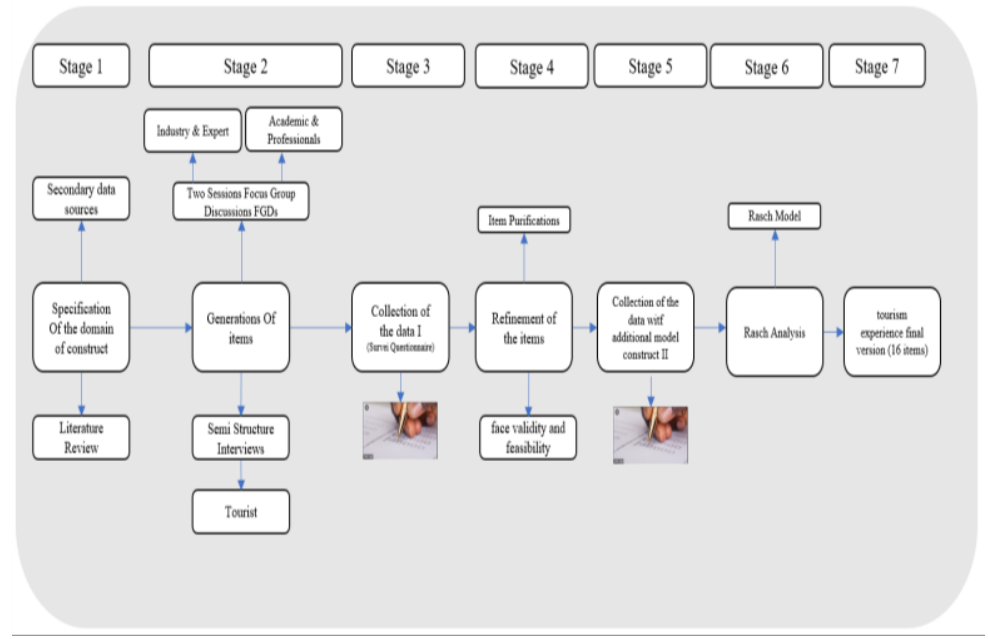

Figure 1. Research Design and Process
Table 2.The Profile of Research Respondents

\begin{tabular}{|l|c|c|}
\hline Variable & Frequency & Per cent \\
\hline Gender & & \\
\hline Male & 157 & $42.09 \%$ \\
\hline Female & 216 & $57.91 \%$ \\
\hline Age & & \\
\hline $17-25$ & 149 & $39.95 \%$ \\
\hline $26-45$ & 217 & $58.17 \%$ \\
\hline$>=45$ & 7 & $1.88 \%$ \\
\hline Education & & \\
\hline High school & 76 & $20.38 \%$ \\
\hline Diploma & 161 & $43.16 \%$ \\
\hline Undergraduate & 121 & $32.44 \%$ \\
\hline Graduate & 15 & $4.02 \%$ \\
\hline Household income per month & & \\
\hline Visitor & 101 & $27.08 \%$ \\
\hline Resident & 272 & $72.92 \%$ \\
\hline
\end{tabular}

\section{RESULTS DISCUSSIONS}

This study uses a quantitative approach, namely quantifying respondent's answers on a nominal scale and Likert rating then inputting the statistical data into the parent table or tabulation to be processed with the Winstep software from the Rasch Model (Miftahuddin et al., 2020). The study design used is a descriptive explanation. Which describes the characteristics of respondents and the quality of statement items developed from each variable and then explains the results of research-based Winstep software. The data sources in this study are respondents in tourism visitors in Indonesia. The number of respondents is 373 people with a purposive sampling technique seen in Table 2. Data analysis techniques using Rasch Model are by measuring and analyzing the quality of statements developed from each research variable and measuring the quality of respondents based on answers to the statements given. Next, discuss and conclude the results of the research. The framework of this study is a quantitative one method where pre-experimental nature is used to evaluate the phenomenon. The data collected shall be processed by the standards to be defined between empiric observations and quantitative observations basic mathematics. Principal data has been obtained via a questionnaire built and provided on-line. Data collected by questionnaires are analyzed using a Rasch analysis and the test method allows Likert data collected through questionnaires to be turned into intervals (Bond and Fox, 2020).

It should be mentioned that the Rasch model is the most effective approach to basic human science study where instruments (questionnaires) are used and measurements yield ordinal results. Cavanagh and Waugh (2011) revealed that the Rasch model, based on probability, enables users to accurately predict the response into all items of the measurement items, using only the parameters (such as the size of the person) and the parameters of the items on the same scale (such as the complexity measurement parameter). The Rasch model converts the number of items measured also on the Likert scale (which is the ordinal data) into an interval scale called the Likert scale. The likert scale "logarithmic units of probability" (logit). Statistics suitability of items and people shows the extent of the data obtained is appropriate, reliable, and following the basic steps, as well as provide information about the quality of measurements. Results have been tabulated using Microsoft Excel application and processed using the Winstep 3.7 software. Data that had acceptable measurement intervals and met all the requirements for the validity and reliability of the system were analyzed using the Rasch Model.

\section{Summary Statistics}

Summary statistics are presents cumulative information on quality of the respondents as a whole, quality of the resources used, and the interactions between objects and people. The person measure $=3.10$ logit showing the average value of the respondents in the tourism experience instrument. An average value of more than a logit of 0.0 indicates a tendency for respondents to answer more agreeably to statements on various items. Cronbach alpha in this study was 0.95 , Cronbach alpha was used to measure the reality, namely the interaction between person and item as a whole seen in Table 3. This shows that tourists have felt satisfied with the existing tourist facilities in West Bandung Regency.

\section{Rating Scale}

The validity analysis of the rating scale is used to verify whether the rating options used are confusing to respondents or not. The Andrich Threshold value moves from none to negative and continues to lead to positive overall, this shows that the options given are valid for respondents seen in Table 4. 
Table 3. Summary Statistics of 373 Measured (Extreme and Non-Extreme) Person

\begin{tabular}{|l|c|c|c|c|c|c|c|c|}
\hline & TOTAL & \multirow{2}{*}{ COUNT } & \multicolumn{2}{|c|}{ MODEL } & \multicolumn{2}{c|}{ INFIT } & \multicolumn{2}{c|}{ OUTFIT } \\
\cline { 4 - 9 } & SCORE & & MEASURE & ERROR & MNSQ & ZSTD & MNSQ & ZSTD \\
\hline MEAN & 73.5 & 18 & 3.1 & 0.62 & 0 & 0 & 0 & 0 \\
\hline S.D. & 8.6 & 0 & 2.43 & 0.32 & 0 & 0 & 0 & 0 \\
\hline MAX. & 90 & 18 & 9.29 & 1.84 & 0 & 0 & 0 & 0 \\
\hline MIN. & 18 & 18 & -6.95 & 0.3 & 0.05 & -3.1 & 0.04 & -3.2 \\
\hline REAL RMSE .75 TRUE SD & 2.31 SEPARATION 3.08 Person RELIABILITY .90 \\
\hline
\end{tabular}

Table 4. Rating Scale Summary of Category Structure Model="R"

\begin{tabular}{|c|c|c|c|c|c|c|c|c|c|c|}
\hline CATE & GORY & OBSER & $\mathrm{ED}$ & OBSVD & SAMPLE & \begin{tabular}{|l|} 
INFIT \\
\end{tabular} & OUTFIT & ANDRICH & CATEGORY & \\
\hline LABEL & SCORE & COUNT & $\%$ & AVRGE & EXPECT & MNSQ & MNSQ & THRESHOLD & MEASURE & \\
\hline 1 & 1 & 37 & 1 & -0.3 & -1.6 & 1.85 & 3.1 & NONE & $(-4.10)$ & 1 \\
\hline 2 & 2 & 88 & 1 & -0.34 & -0.7 & 1.21 & 1.55 & -2.7 & -2.52 & 2 \\
\hline 3 & 3 & 735 & 11 & 0.57 & 0.69 & 0.97 & 0.86 & -2.17 & -1.01 & 3 \\
\hline 4 & 4 & 4271 & 64 & 2.55 & 2.56 & 0.86 & 0.84 & -0.17 & 2.44 & 4 \\
\hline 5 & 5 & 1583 & 24 & 5.18 & 5.13 & 1.01 & 0.91 & 5.04 & $(6.14)$ & 5 \\
\hline
\end{tabular}

Table 5. Unidimensionality of Standardized Residual Variance (In Eigenvalue Units)

\begin{tabular}{|l|rr|r|r|r|}
\hline & \multicolumn{3}{|c|}{- Empirical -- } & Modeled \\
\hline Total raw variance in observations & $=$ & 33.3 & $100.00 \%$ & 0 & $100.00 \%$ \\
\hline Raw variance explained by measures & $=$ & 15.3 & $46.00 \%$ & 0 & $46.60 \%$ \\
\hline Raw variance explained by persons & $=$ & 12.1 & $36.20 \%$ & 0 & $36.60 \%$ \\
\hline Raw Variance explained by items & $=$ & 3.3 & $9.80 \%$ & 0 & $9.90 \%$ \\
\hline Raw unexplained variance (total) & $=$ & 18.0 & $54.00 \%$ & $100.00 \%$ & $53.40 \%$ \\
\hline Unexplned variance in 1st contrast & $=$ & 2.6 & $7.80 \%$ & $14.40 \%$ & 0 \\
\hline Unexplned variance in 2nd contrast & $=$ & 2.2 & $6.50 \%$ & $12.00 \%$ & 0 \\
\hline Unexplned variance in 3rd contrast & $=$ & 1.7 & $5.10 \%$ & $9.40 \%$ & 0 \\
\hline Unexplned variance in 4th contrast & $=$ & 1.7 & $5.00 \%$ & $9.30 \%$ & 0 \\
\hline Unexplned variance in 5th contrast & $=$ & 1.5 & $4.40 \%$ & $8.20 \%$ & 0 \\
\hline
\end{tabular}

\section{Unidimensionality}

Unidimensionality is used to evaluate whether the instrument developed can measure what should be measured, in this case, the tourism experience constructs, the $46 \%$ raw variance value has met the $20 \%$ minimum unidimensionality requirement, this shows that the instrument created is sufficient to measure the tourism experience construct seen in Table 5.

\section{Item Measure}

Item measure used to determine the item most difficult is approved and the item most easily approved by the respondent, the measurements made item N16 is a place that has cultural attractions you want to visit an item that is hard to be approved by the respondents, while N1 that tourists get a new experience once traveled is the item most easily approved seen in Table 6.

Table 6. Item Person Statistics: Measure Order

\begin{tabular}{|c|c|c|c|c|c|c|c|c|c|c|c|c|c|}
\hline ENTRY & TOTAL & \multicolumn{2}{|c|}{ TOTAL } & MODEL & \multicolumn{2}{|c|}{ INFIT } & \multicolumn{2}{|c|}{ OUTFIT } & \multicolumn{2}{|c|}{ PT-MEASURE } & EXACT & MATCH & Itam \\
\hline $\mathrm{NO}$ & SCORE & COUNT & MEASURE & S.E. & MNSQ & ZSTD & MNSQ & ZSTD & CORR. & EXP. & OBS\% & EXP\% & Item \\
\hline 16 & 1409 & 373 & 1.39 & 0.1 & 1.36 & 3.6 & 1.51 & 4.6 & 0.63 & 0.72 & 64.8 & 69.1 & N16 \\
\hline 14 & 1452 & 373 & 0.93 & 0.11 & 0.95 & -0.5 & 1.08 & 0.8 & 0.7 & 0.72 & 74.1 & 71.4 & N14 \\
\hline 17 & 1483 & 373 & 0.56 & 0.11 & 1.37 & 3.5 & 1.34 & 3 & 0.64 & 0.71 & 71.3 & 73.3 & N17 \\
\hline 9 & 1488 & 373 & 0.5 & 0.11 & 1.45 & 4.2 & 1.46 & 3.9 & 0.69 & 0.71 & 66.2 & 73.5 & N9 \\
\hline 13 & 1499 & 373 & 0.36 & 0.11 & 0.81 & -2.1 & 0.76 & -2.4 & 0.74 & 0.71 & 84.4 & 74.2 & N13 \\
\hline 5 & 1515 & 373 & 0.14 & 0.12 & 0.91 & -1 & 0.89 & -1 & 0.75 & 0.71 & 74.7 & 75.1 & N5 \\
\hline 18 & 1515 & 373 & 0.14 & 0.12 & 1.09 & 0.9 & 1.01 & -0.1 & 0.71 & 0.71 & 77.8 & 75.1 & N8 \\
\hline 6 & 1521 & 373 & 0.06 & 0.12 & 0.91 & -0.9 & 0.85 & -1.4 & 0.75 & 0.71 & 76.1 & 75.4 & N6 \\
\hline 2 & 1529 & 373 & -0.05 & 0.12 & 1 & 0.1 & 1 & 0 & 0.69 & 0.71 & 78.7 & 75.6 & N2 \\
\hline 4 & 1529 & 373 & -0.05 & 0.12 & 0.72 & -3.2 & 0.7 & -3 & 0.76 & 0.71 & 80.4 & 75.6 & N4 \\
\hline 15 & 1533 & 373 & -0.11 & 0.12 & 0.76 & -2.7 & 0.64 & -3.8 & 0.77 & 0.71 & 83 & 75.8 & N15 \\
\hline 11 & 1542 & 373 & -0.23 & 0.12 & 1.03 & 0.3 & 0.92 & -0.7 & 0.69 & 0.7 & 76.7 & 76.1 & N11 \\
\hline 7 & 1549 & 373 & -0.34 & 0.12 & 0.83 & -1.8 & 0.71 & -2.9 & 0.7 & 0.7 & 80.7 & 76.4 & N7 \\
\hline 12 & 1549 & 373 & -0.34 & 0.12 & 0.94 & -0.6 & 0.81 & -1.8 & 0.74 & 0.7 & 79.8 & 76.4 & N12 \\
\hline 8 & 1553 & 373 & -0.4 & 0.12 & 0.96 & -0.4 & 0.89 & -1 & 0.69 & 0.7 & 78.4 & 76.6 & N8 \\
\hline 3 & 1572 & 373 & -0.68 & 0.12 & 0.76 & -2.8 & 0.69 & -3.1 & 0.74 & 0.69 & 83.5 & 76.9 & N3 \\
\hline 10 & 1586 & 373 & -0.9 & 0.12 & 1.18 & 1.9 & 1.05 & 4 & 0.69 & 0.69 & 78.1 & 77 & N10 \\
\hline 1 & 1593 & 373 & -0.1 & 0.12 & 0.88 & -1.3 & 0.82 & -1.6 & 0.69 & 0.68 & 81.8 & 76.9 & N1 \\
\hline MEAM & 1523.2 & 379 & 0 & 0.12 & 1 & -0.2 & 0.95 & -0.6 & & & 77.3 & 75 & \\
\hline S.D. & 44.5 & 0 & 0.59 & 0.01 & 0.21 & 0.01 & 0.25 & 2.3 & & & 5.3 & 2 & \\
\hline
\end{tabular}

\section{Person measure}

The person measure is used to find out respondents who have a high sense of tourism experience compared to other respondents, in this study, it is seen that $003 \mathrm{PZ}$ respondents, namely respondent number 3 , women, and who live from outside the city have a high sense of tourism experience compared to other respondents seen in Table 7.

\section{Variable Map}

That variable map displays the share of tourist skills and questions on same logit scale. Tourist skills are displayed on the left side of the map, whereas the difficulty level of the item is now on the right side of both the logit map. High logits are tourists with higher skills (left side) and more challenging things (right side) and vice versa (Iramaneerat et al., 2008). It helps researchers to classify items that meet the standards of visitors via a variable map. Logit 0 is given as the average of the items in question. First from variable map, we see that the majority of tourists are above averages of the things in 
Question. Higher tourist expectations were set at +9.29 logit and some tourists who knew they did not live up to their expectations after visiting-6.95 logit. The value of the logits shall be obtained from the min and max size. Thus we can express the aspirations of the tourists that come, in line with the answers given and the reality of the area. We also note that there are two difficult things above log 0, namely N16 and N14 seen in figure 2. It is therefore proposed that these two elements should be omitted and strengthened by adding other item that could better distinguish the preferences of visitors.

Table 7. Person measure

\begin{tabular}{|c|c|c|c|c|c|c|c|c|c|c|c|c|c|}
\hline \multirow{2}{*}{$\begin{array}{c}\text { ENTRY } \\
\text { NUMBER }\end{array}$} & \multirow{2}{*}{$\begin{array}{l}\text { TOTAL } \\
\text { SCORE } \\
\end{array}$} & \multirow{2}{*}{$\begin{array}{l}\text { TOTAL } \\
\text { COUNT }\end{array}$} & \multirow{2}{*}{ MEASURE } & \multirow{2}{*}{$\begin{array}{c}\text { MODEL } \\
\text { S.E. }\end{array}$} & \multicolumn{2}{|c|}{ INFIT } & \multicolumn{2}{|c|}{ OUTFIT } & \multirow{2}{*}{$\begin{array}{c}\text { PT- } \\
\text { MEASURE } \\
\text { CORR. }\end{array}$} & \multirow[b]{2}{*}{ EXP. } & \multirow{2}{*}{$\begin{array}{c}\text { EXACT } \\
\text { OBS\% }\end{array}$} & \multirow{2}{*}{$\begin{array}{c}\text { МАТСH } \\
\text { EXP\% }\end{array}$} & \multirow{2}{*}{ Person } \\
\hline & & & & & MNSQ & ZSTD & MNSQ & ZSTD & & & & & \\
\hline 3 & 90 & 18 & 9.29 & 1.84 & \multicolumn{4}{|c|}{ MAXIMUM MEASURE } & 0 & 0 & 100 & 100 & 003PZ \\
\hline 20 & 90 & 18 & 9.29 & 1.84 & \multicolumn{4}{|c|}{ MAXIMUM MEASURE } & 0 & 0 & 100 & 100 & 020PZ \\
\hline 22 & 90 & 18 & 9.29 & 1.84 & \multicolumn{4}{|c|}{ MAXIMUM MEASURE } & 0 & 0 & 100 & 100 & 022PZ \\
\hline 53 & 90 & 18 & 9.29 & 1.84 & \multicolumn{4}{|c|}{ MAXIMUM MEASURE } & 0 & 0 & 100 & 100 & 053LB \\
\hline 107 & 90 & 18 & 9.29 & 1.84 & \multicolumn{4}{|c|}{ MAXIMUM MEASURE } & 0 & 0 & 100 & 100 & $107 \mathrm{LZ}$ \\
\hline 130 & 90 & 18 & 9.29 & 1.84 & \multicolumn{4}{|c|}{ MAXIMUM MEASURE } & 0 & 0 & 100 & 100 & 130LZ \\
\hline 203 & 90 & 18 & 9.29 & 1.84 & \multicolumn{4}{|c|}{ MAXIMUM MEASURE } & 0 & 0 & 100 & 100 & 203PZ \\
\hline 208 & 90 & 18 & 9.29 & 1.84 & \multicolumn{4}{|c|}{ MAXIMUM MEASURE } & 0 & 0 & 100 & 100 & 208PZ \\
\hline 210 & 90 & 18 & 9.29 & 1.84 & \multicolumn{4}{|c|}{ MAXIMUM MEASURE } & 0 & 0 & 100 & 100 & $210 \mathrm{PZ}$ \\
\hline 212 & 90 & 18 & 9.29 & 1.84 & \multicolumn{4}{|c|}{ MAXIMUM MEASURE } & 0 & 0 & 100 & 100 & 212PZ \\
\hline 221 & 90 & 18 & 9.29 & 1.84 & \multicolumn{4}{|c|}{ MAXIMUM MEASURE } & 0 & 0 & 100 & 100 & $221 \mathrm{LB}$ \\
\hline 227 & 90 & 18 & 9.29 & 1.84 & \multicolumn{4}{|c|}{ MAXIMUM MEASURE } & 0 & 0 & 100 & 100 & $227 \mathrm{LB}$ \\
\hline 241 & 90 & 18 & 9.29 & 1.84 & \multicolumn{4}{|c|}{ MAXIMUM MEASURE } & 0 & 0 & 100 & 100 & $241 \mathrm{LZ}$ \\
\hline 243 & 90 & 18 & 9.29 & 1.84 & \multicolumn{4}{|c|}{ MAXIMUM MEASURE } & 0 & 0 & 100 & 100 & $243 \mathrm{~PB}$ \\
\hline 281 & 90 & 18 & 9.29 & 1.84 & \multicolumn{4}{|c|}{ MAXIMUM MEASURE } & 0 & 0 & 100 & 100 & $281 \mathrm{LB}$ \\
\hline 294 & 90 & 18 & 9.29 & 1.84 & \multicolumn{4}{|c|}{ MAXIMUM MEASURE } & 0 & 0 & 100 & 100 & 294LZ \\
\hline 298 & 90 & 18 & 9.29 & 1.84 & \multicolumn{4}{|c|}{ MAXIMUM MEASURE } & 0 & 0 & 100 & 100 & 298PB \\
\hline 335 & 90 & 18 & 9.29 & 1.84 & & XIMUN & MEASt & & 0 & 0 & 100 & 100 & 335LZ \\
\hline 340 & 90 & 18 & 9.29 & 1.84 & & XIMUN & MEASt & & 0 & 0 & 100 & 100 & 340PZ \\
\hline 351 & 90 & 18 & 9.29 & 1.84 & & XIMUN & MEASL & & 0 & 0 & 100 & 100 & $351 \mathrm{PZ}$ \\
\hline 33 & 90 & 18 & 8.03 & 1.04 & 0.92 & 0.2 & 0.49 & -0.2 & 0.38 & 0.15 & 94.4 & 94.4 & 033PZ \\
\hline 179 & 89 & 18 & 8.03 & 1.04 & 0.8 & 0.1 & 0.32 & -0.5 & 0.57 & 0.15 & 94.4 & 94.4 & 179PZ \\
\hline 198 & 89 & 18 & 8.03 & 1.04 & 0.8 & 0.1 & 0.32 & -0.5 & 0.57 & 0.15 & 94.4 & 94.4 & 198PZ \\
\hline 250 & 89 & 18 & 8.03 & 1.04 & 1.02 & 0.3 & 0.83 & 0.2 & 0.15 & 0.15 & 94.4 & 94.4 & $250 \mathrm{LZ}$ \\
\hline 289 & 89 & 18 & 8.03 & 1.04 & 0.8 & 0.1 & 0.32 & -0.5 & 0.57 & 0.15 & 94.4 & 94.4 & $289 \mathrm{~PB}$ \\
\hline
\end{tabular}

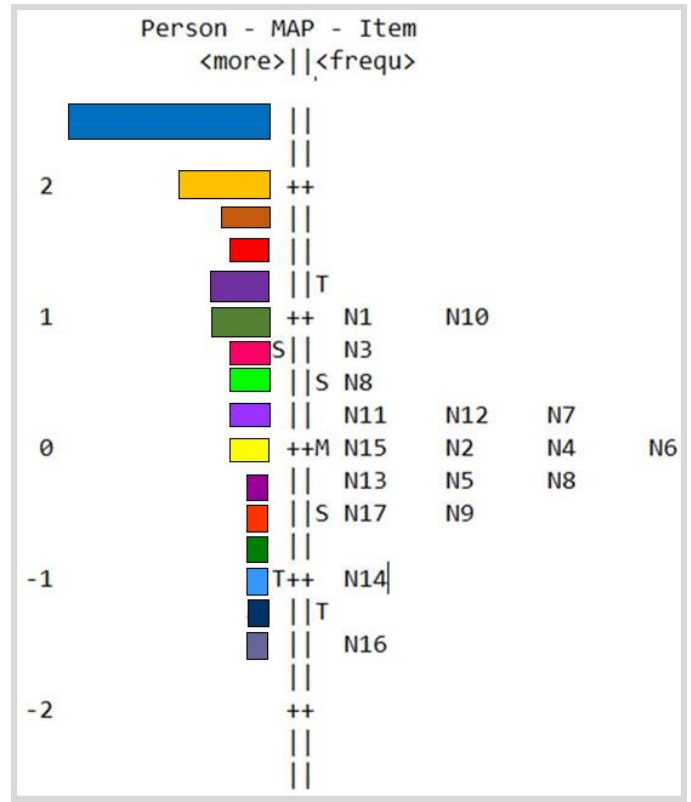

Figure 2. Map of Person and Item

\section{CONCLUSION}

The aim of this experiment is to determine the level wherein the different aspects of the tourism experience in Indonesia main choice are by the population, the study of the selected instrument is carried out using the Rasch evaluation and the results of this research of the instrument show that the experience of tourism is based on the experience of the community instrument is a reliable measuring tool, the tools used are by the required criteria, the increase in tourist preferences for certain items will eventually become an agreement between the items made with the expectations desired by tourists.

The assurance of having a new experience after the tour, tourists having fun and enjoying the tourist location, and freeing tourists from their daily routine are the most important attributes that tourists consider when choosing a tourist spot. Therefore, providers of tourist attractions must ensure that they can provide guarantees for meeting their needs while traveling, run a business by the principles of tourism with a memory-focused experience, and offer high-quality services to the satisfaction of tourists. The effect of this research on tourist attraction managers and the policy is that the understanding and desires of tourists must be increased through coordinated programs between stakeholders. Other implications for managers are also the responsibility of managers to increase the quantity and performance of human capital, to systematize facilities and infrastructure. Interactions with customers with first-rate service management, the flexibility of the tourism products offered, and input from visitors must be awaited. It is suggested future research can examine traveler profiles, which will provide valuable information on tourism segments targeted by tourist managers, thereby facilitating the development of an effective marketing mix. Other means of future study should be to integrate both quantitative and qualitative research with the target of decreasing bias in the perception of measurement devices.

\section{REFERENCES}

Akay, B. (2020). Examining the rural tourism experiences of tourists in emerging rural tourism destination: Burdur Province, Turkey. Geojournal of Tourism and Geosites, 29(2), 534-544. https://doi.org/10.30892/gtg.29212-487

Al-Ansi, A., Han, H., Kim, S.S, \& King, B. (2021). Inconvenient Experiences among Muslim Travelers: An Analysis of the Multiple Causes. Journal of Travel Research, 60(6), 1352-1370. https://doi.org/10.1177/0047287520934870 
Al-Hazmia, N. (2020). A study on the dimensions of the quality of tourism services in the Kingdom of Saudi Arabia. Management Science Letters, 10(5), 1115-1120. https://doi.org/10.5267/j.msl.2019.10.030

Al Mamun, A., Mohiuddin, M., Fazal, S.A., \& Ahmad, G.B. (2018). Effect of entrepreneurial and market orientation on consumer engagement and performance of manufacturing SMEs. Management Research Review. https://doi.org/10.1108/MRR-04-2017-0102

Azara, I., Wiltshier, P., \& Greatorex, J. (2018). Against all odds: Embedding new knowledge for event continuity and community wellbeing. Event Management, 22(1), 25-36. https://doi.org/10.3727/152599517X15111988553964

Bond, T., Yan, Z., \& Heene, M. (2020). Applying the Rasch model: Fundamental measurement in the human sciences. Routledge. https://doi.org/10.4324/9780429030499

Bowen, A. (2019). 'You don't have to say anything': Modality and consequences in conversations about the right to silence in the Northern Territory. Australian Journal of Linguistics, 39(3), 347-374. https://doi.org/10.1080/07268602.2019.1620682

Brakus, J.J., Schmitt, B.H., \& Zarantonello, L. (2009). Brand experience: what is it? How is it measured? Does it affect loyalty?. Journal of marketing, 73(3), 52-68. https://doi.org/10.1509/jmkg.73.3.052

Cavanagh, R.F., \& Waugh, R.F. (2011). Applications of rasch measurement in learning environments research. Springer Science \& Business Medi, 2, (Eds.). https://doi.org/10.1007/978-94-6091-493-5

Chan, A., Suryadipura, D., Kostini, N., \& Miftahuddin, A. (2021). An integrative model of cognitive image and city brand equity. Geojournal of Tourism and Geosites, 35(2), 364-371. https://doi.org/10.30892/gtg.35214-660

Chugh, S.R. (2018). Creative tourism: An endogenous approach to developing culturally and environmentally sustainable tourism. International Journal of Hospitality and Tourism Systems, 11(1), 60.

Cohen, E. (1979). A phenomenology of tourist experiences. Sociology, 13(2), 179-201. https://doi.org/10.1177/003803857901300203

Csikszentmihalyi, M. (2009). Flow: The Psychology of Optimal Experience [Resenha].

Iramaneerat, C.H.E.R.D.S.A.K., Smith Jr, E.V., \& Smith, R.M. (2008). An introduction to Rasch measurement. Best practices in quantitative methods, 50-70. https://doi.org/10.4135/9781412995627.d6

Jepson, D., \& Sharpley, R. (2015). More than sense of place? Exploring the emotional dimension of rural tourism experiences. Journal of Sustainable Tourism, 23(8-9), 1157-1178. https://doi.org/10.1080/09669582.2014.953543

Junaidi, J. (2020). Halal-friendly tourism and factors influencing halal tourism. Management Science Letters, 10(8), $1755-1762$. https://doi.org/10.5267/j.msl.2020.1.004

Jung, T., tom Dieck, M.C., Lee, H., \& Chung, N. (2016). Effects of virtual reality and augmented reality on visitor experiences in museum. In Information and communication technologies in tourism, 621-635, Springer, Cham. https://doi.org/10.1007/978-3-319-28231-2_45

Kirillova, K., \& Wassler, P. (2019). Travel Beautifully: The Role of Aesthetics in Experience Design. In Atmospheric Turn in Culture and Tourism: Place, Design and Process Impacts on Customer Behaviour, Marketing and Branding. Emerald Publishing Limited. https://doi.org/10.1108/S1871-317320190000016017

Kóródi, M., Mondok, A., Dávid, L.D., \& Szabó, A. (2020). Motivations and experiences concepts in the travel decisions of domestic tourists of the "Hungarian great plain". Geojournal of Tourism and Geosites, 32(4), 1347-1354. https://doi.org/10.30892/gtg.32423-579

Lebrun, A.M., Su, C.J., \& Bouchet, P. (2021). Domestic tourists' experience in protected natural parks: A new trend in pandemic crisis? Journal of Outdoor Recreation and Tourism, 35. https://doi.org/10.1016/j.jort.2021.100398

Manthiou, A., Hickman, E., \& Klaus, P. (2020). Beyond good and bad: Challenging the suggested role of emotions in customer experience (CX) research. Journal of Retailing and Consumer Services, 57, 102218. https://doi.org/10.1016/j.jretconser.2020.102218

Miftahuddin, A., Hermanto, B., Raharja, S.U.J., \& Chan, A. (2020). City Brand Attractiveness on Tourism using Rasch Model Approach. Int. J Sup. Chain. Mgt, 9(2), 150.

Miftahuddin, A. (2021). City branding and its variables: The evidence from Indonesia. Geojournal of Tourism and Geosites, 34(1), 240244. https://doi.org/10.30892/GTG.34132-643

Nguyen, Q., Nguyen, H., \& Le, T. (2020). Relationships among novelty seeking, satisfaction, return intention, and willingness to recommend of foreign tourists in Vietnam. Management Science Letters, 10(10), 2249-2258. https://doi.org/10.5267/j.msl.2020.3.011

Olsson, A.K. (2016). Canals, rivers and lakes as experiencescapes-destination development based on strategic use of inland water. International Journal of Entrepreneurship and Small Business, 29(2), 217-243. https://doi.org/10.1504/IJESB.2016.078696

Ponte, J., Couto, G., Sousa, Á., Pimentel, P., \& Oliveira, A. (2021). Idealizing adventure tourism experiences: tourists' self-assessment and expectations. Journal of Outdoor Recreation and Tourism, 35. https://doi.org/10.1016/j.jort.2021.100379

Rasoolimanesh, S.M., Seyfi, S., Hall, C.M., \& Hatamifar, P. (2021). Understanding memorable tourism experiences and behavioural intentions of heritage tourists. Journal of Destination Marketing and Management, 21. https://doi.org/10.1016/j.jdmm.2021.100621

Ritchie, J., \& Hudson, S. (2009). Understanding and meeting the challenge of consumer/tourist experience research. International Journal of Tourism Research, 11, 111-126. https://doi.org/10.1002/jtr.721

Setini, M., Wardana, I., Sukaatmadja, I., Ekawati, N., Yasa, N., \& Astawa, I. (2020). Policy models for improving ecotourism performance to build quality tourism experience and sustainable tourism. Management Science Letters, 11(2), 595-608. https://doi.org/10.5267/j.msl.2020.9.007

Soh, S.E., Morello, R., Ayton, D., Ahern, S., Scarborough, R., Zammit, C., \& Zalcberg, J. (2021). Measurement properties of the 12 -item Short Form Health Survey version 2 in Australians with lung cancer: a Rasch analysis. Health and Quality of Life Outcomes, 19(1). https://doi.org/10.1186/s12955-021-01794-w

Stolt, M., Kottorp, A., \& Suhonen, R. (2021). A Rasch analysis of the self-administered Foot Health Assessment Instrument (S-FHAI). BMC Nursing, 20(1). https://doi.org/10.1186/s12912-021-00625-z

Tresna, P.W., Chan, A., \& Alexandri, M.B. (2019). Place branding as Bandung City's competitive advantage. International Journal of Economic Policy in Emerging Economies, 12(2), 182-189. https://doi.org/10.1504/IJEPEE.2019.099698

Uriely, N. (2005). The tourist experience: Conceptual developments. Annals of Tourism research, 32(1), $199-216$. https://doi.org/10.1016/j.annals.2004.07.008

Pine, B.J., \& Gilmore, J.H. (2011). The experience economy. Harvard Business Press.

Pucihar, A., Lenart, G., Kljajić Borštnar, M., Vidmar, D., \& Marolt, M. (2019). Drivers and outcomes of business model innovationMicro, small and medium-sized enterprises perspective. Sustainability, 11(2), 344. https://doi.org/10.3390/su11020344

Vollero, A., Conte, F., Bottoni, G., \& Siano, A. (2018). The influence of community factors on the engagement of residents in place promotion: Empirical evidence from an Italian heritage site. International Journal of Tourism Research, 20(1), 88-99. https://doi.org/10.1002/jtr.2164

Walters, N.H., \& Cassel, S.H. (2016). Still a white paradise? Photographic representations of Jamaica as a tourism destination. Tourism Culture \& Communication, 16(1-2), 59-73. https://doi.org/10.3727/109830416X14655571061755

Xie, X., Zeng, S., Peng, Y., \& Tam, C. (2013). What affects the innovation performance of small and medium-sized enterprises in China?. Innovation, 15(3), 271-286. https://doi.org/10.5172/impp.2013.15.3.271 